\title{
Cardiovascular Effects of the Treatment of Respiratory Distress Syndrome and Associated Morbidities of Prematurity
}

Alan M Fujii*

Department of Pediatrics, Boston Medical Center, Boston University School of Medicine, USA

\begin{abstract}
Neonatal Respiratory Distress Syndrome (RDS), caused by surfactant deficiency, is a primary cause of neonatal morbidity and mortality in premature infants in the United States. The pathophysiology of RDS, however, involves more than surfactant deficiency and decreased pulmonary compliance. There is an intricate interaction of pulmonary and cardiovascular contributors to the pathophysiology. The consequences of the treatment of RDS and its associated morbidities may increase the risk for additional morbidities. The purpose of this review is to describe the cardiovascular responses to RDS and its treatment in preterm infants. Topics include the significance of the cardiovascular system in the natural history and treatment of RDS, from antenatal care through the evolution of chronic lung disease. The discussion reviews what is known, what needs to be known, and how neonatologists may increase their awareness of these underappreciated consequences in the future.
\end{abstract}

Keywords: Neonatal Respiratory Distress Syndrome (RDS); Premature infants; Cardiovascular; Hemodynamics; Surfactant

Abbreviations: AMV: Avoidance of Mechanical Ventilation without Intubation; BPD: Bronchopulmonary Dysplasia; CAP: Caffeine for Apnea of Prematurity; COIN: Continuous Positive Airway Pressure or Intubation at Birth Tial; CPAP: Continuous Positive Airway Pressure Pressure; CURPAP: Prophylactic or Slective Curosurf with CPAP; HIF: Hypoxia-Inducible Factor 1/2 alpha; iNO: inhaled Nitric Oxide; IVH: Intraventricular Hemorrhage; MIST: Minimally Invasive Surfactant Therapy without intubation; NEC: Necrotizing Enterocolitis; PDA: Patent Ductus Arteriosus; PVL: Periventricular Leukomalacia; RDS: Neonatal Respiratory Distress Syndrome; SUPPORT: Surfactant Positive Pressure, and Oxygenation Randomized Trial; TC: Take Care, surfactant administration without intubation; TIPP: Trial of Indomethacin Prophylaxis in Preterms; VEGF: Angiogenic factor Vascular Endothelial Growth Factor

\section{Introduction}

Neonatal Respiratory Distress Syndrome (RDS) is due to surfactant deficiency, and remains a primary cause of neonatal morbidity and mortality in the United States. The pathophysiology of RDS, however, involves more than surfactant deficiency and decreased pulmonary compliance $[1,2]$. There is an intricate interaction of cardiovascular factors involved in the treatment of RDS and the associated morbidities of prematurity. These effects are direct, indirect, and reflex-mediated. This review will discuss the cardiovascular responses to RDS and its treatment in preterm infants from antenatal care through the evolution of chronic lung disease, and how use of existing technology may improve management of these cardiovascular challenges.

\section{Antenatal Steroid Prophylaxis}

Antenatal corticosteroid administration to the high-risk mother with threatened preterm delivery, in combination with regionalization of high-risk obstetrical care, has decreased the incidence and severity of major morbidities of prematurity, including RDS, Intraventricular Hemorrhage (IVH), Necrotizing Enterocolitis (NEC), and Patent Ductus Arteriosus (PDA) [3,4]. Nonetheless, RDS and the associated morbidities of prematurity continue to be major problems for premature infants [5-7]. While extensive research shows that antenatal corticosteroid administration increases surfactant production and secretion, it also reduces cellular division and decreases cerebral myelination in fetal sheep [8,9]. Betamethasone, the most commonly used antenatal corticosteroid, is cleared from the fetal circulation within 48 hours of administration. The effect of antenatal steroids on surfactant production appears durable, and repeated antenatal steroids may not be necessary [10]. In fact, antenatal corticosteroids given weekly may increase the frequency of cerebral palsy [11]. In addition, the combination of recently administered antenatal steroids and administration of indomethacin in the first 2-3 days of life may increase the frequency of NEC with perforation and spontaneous intestinal perforation [12-14]. While the etiologic mechanism of spontaneous focal intestinal perforation is controversial and may not be vascular [15], we include it as a potential vascular consequence of established therapies. The combination of corticosteroid and indomethacin is now avoided whenever possible in premature neonates, due to the association with spontaneous intestinal perforation [16]. Thus, while evidence-based medicine supports the use of prophylactic antenatal steroids, there is controversy regarding repeated use and the use of indomethacin following recent maternal antenatal corticosteroid administration.

\section{Surfactant Therapy}

Surfactant and mechanical ventilation remains the mainstay of severe RDS management in the NICU. However, intratracheal administration of the liquid surfactant, beractant $(4 \mathrm{ml} / \mathrm{kg})$, in infants with RDS may be associated with transient conducting airway obstruction, hypoventilation, hypercarbia, and an increase in cerebral blood flow [17]. Hypercarbia and the increase in cerebral blood flow may be avoided using smaller volumes of a more concentrated surfactant, poractant alfa $(1.25 \mathrm{ml} / \mathrm{kg})$, and a volume cycle ventilator delivering consistent minute ventilation [18]. When surfactant is first administered, the rapid improvement in pulmonary compliance may result in a transient hyperventilation, hypocarbia and a decrease in

*Corresponding author: Alan Fujii, MD, Department of Pediatrics, Boston Medical Center, Boston University School of Medicine, One Boston Medical Center Place, Boston, MA 02118, USA, Tel: 617-414-5461; Fax: 617-414-7297; E-mail: alan.fujii@bmc.org

Received December 19, 2012; Accepted July 25, 2013; Published July 29, 2013

Citation: Fujii AM (2013) Cardiovascular Effects of the Treatment of Respiratory Distress Syndrome and Associated Morbidities of Prematurity. J Pulmon Resp Med S13: 005. doi:10.4172/2161-105X.S13-005

Copyright: (c) 2013 Fujii AM. This is an open-access article distributed under the terms of the Creative Commons Attribution License, which permits unrestricted use, distribution, and reproduction in any medium, provided the original author and source are credited. 
cerebral blood flow [18]. Changes in cerebral blood flow may persist for an hour.

Surfactant-induced improvement in oxygenation reduces pulmonary vascular resistance and an increase in flow through a PDA [19]. Again, these hemodynamic changes in ductal blood flow may be virtually eliminated by using small surfactant volumes while maintaining consistent minute ventilation with volume cycle ventilation and consistent arterial oxygen saturation levels $[18,20]$. Non-invasive administration of aerosolized surfactant may minimize the cardiovascular effects of surfactant administration.

New strategies may allow administration of surfactant without intubation or mechanical ventilation. Avoidance of Mechanical Ventilation Surfactant Administration (AMV) was developed by Kribs et al. [21,22]. They used Magill forceps to advance a soft catheter into the trachea of infants receiving CPAP support for moderate RDS. A multicenter randomized control study, in 2011, found significantly fewer infants on invasive mechanical ventilation at 3 days of life and observed that surfactant therapy reduced the frequency of chronic lung disease in both studies without affecting mortality $[21,22]$. It is uncertain whether these results would be replicated when means other than a gas jet-induced CPAP are used. Dargaville et al. [23,24] described use of a stiff vascular catheter to provide Minimally Invasive Surfactant Therapy (MIST), using a 16 gauge vascular catheter without intubation, Magill forceps or sedation in 61 infants 25-28 weeks and 29-32 weeks gestation. When compared with historical controls, infants 25-28 weeks had less need for invasive mechanical ventilation at 72 hours (32\% vs $68 \%$ ), and duration of oxygen therapy was less in the MIST group. The authors concluded that MIST is a technique worthy of further study. Both tracheal cannulation techniques require skill in direct larnygoscopic visualization and placement of the catheters, but offer the potential benefits of early surfactant administration without the consequences of intubation and mechanical positive pressure ventilation.

A technique for minimally invasive surfactant administration in non-intubated, spontaneously breathing premature infants, using a shortened soft, small caliber catheter was described by Gopel [25] and called Avoidance Of Mechanical Ventilation (AMV). Early surfactant administration decreased the need for mechanical ventilation, but did not lower the frequency of BPD. A similar technique of early surfactant administration through a soft catheter was used by Kanmaz et al. [26], called Take Care (TC, no intubation), in infants $<32$ weeks and compared with InSurE (intubated $30 \mathrm{sec}$ for surfactant administration, extubate). In a randomized control trial, poractant alfa, $1.25 \mathrm{ml} / \mathrm{kg}$, was administered by TC $(n=100)$ or InSurE $(n=100)$. Infants in the TC group had a significantly lower mechanical ventilation rate $(30 \%$ vs. $45 \%, \mathrm{p}=0.02)$, duration of $\mathrm{nCPAP}$ and mechanical ventilation, and frequency of BPD (13.6\% vs $26.2 \%, p=0.008)$ than infants in InSurE group. The study suggests that intubation and even brief positive pressure mechanical ventilation may cause significant lung injury. While intratracheal surfactant administration of $100 \mathrm{mg} /$ $\mathrm{kg}$ of poractant alfa is less than the first dose recommended by the manufacture, nor the dose associated with a lower the mortality rate in VLBW premature infants, the study supports the need for additional studies in this area. Administration of surfactant to non-intubated, spontaneously breathing infants may be associated with greater changes in ventilation than in an intubated, mechanically ventilated infant, with potentially greater changes in cerebral blood flow. On the other hand, the low surfactant volume (poractant alfa, $1.25 \mathrm{ml} / \mathrm{kg}$ ) may be sufficiently small to avoid the conducting airway obstruction described with larger surfactant volumes. These techniques for MIST, AMV, TC and InSurE are promising, but require additional research validation before they can be recommended. Research methods to non-invasively monitor lung volumes and minute ventilation may become important in the understanding of the lung volumes associated with injury and development of BPD in infants receiving and not receiving positive pressure mechanical ventilation.

Nebulized or aerosolized surfactants are currently being tested in clinical trials to provide a non-invasive, atraumatic mode of surfactant delivery requiring only modest technical expertise. Previous trials of aerosolized surfactant preparations have been largely ineffective, but Phase 2 studies with lucinactant (Aerosurf ${ }^{\circledast}$ ) show some promise [27]. Further clinical research regarding dosing, surfactant delivery, and comparison with conventional therapies are needed, and the effects of these alternative techniques on $\mathrm{pCO}_{2}$ and regional blood flow have yet to be determined.

\section{Mechanical Ventilation Strategies}

Respiratory support strategies for premature infants with RDS using surfactant and invasive and non-invasive ventilation have changed dramatically over the past decade, reducing the frequency of chronic lung disease and pulmonary air leak $[28,29]$. These changes were prompted by reports that extensive use of continuous positive airway pressure (CPAP) and avoidance of invasive mechanical ventilation and surfactant administration achieved the lowest rates of bronchopulmonary dysplasia [30-32]. Randomized control trials have consistently demonstrated the benefit of early CPAP and rescue surfactant over prophylactic intubation and surfactant administration [33-38].

Current strategies in the NICU for patients requiring intubation and positive pressure mechanical ventilation focus on minimizing invasive positive pressure volume-induced (volutrauma) and pressure-induced pulmonary damage (barotrauma) [39]. Volumecycle ventilation, using rapid rates and low tidal volumes minimizes volutrauma, resulting in a lower incidence of air leak syndrome, even though there may be no change in the frequency of chronic lung disease [40]. Furthermore, oxidant and free-radical lung injury caused by high levels of supplemental oxygen are being minimized by using lower oxygen saturation targets for very premature infants $[41,42]$. Inflammatory responses to lung epithelial damage presages the development of Bronchopulmonary Dysplasia (BPD) $[43,44]$. This inflammatory process can be managed with the use of systemic and inhaled steroids and lowering of oxygen saturation targets. While the primary pulmonary response to supplemental oxygen is pulmonary vasodilation, the consequences of chronic lung disease and lung injuryinduced pulmonary hypoplasia may be pulmonary hypertension. The BPD now induced in the extremely low birth weight infant is probably a combination of altered vascular and dysplastic alveolar development combined with pulmonary vasoconstriction [45-48]. This condition may be different than the BPD originally described by Northway et al. [49].

To minimize invasive positive pressure ventilation, neonatologists have become more tolerant of hypercarbia and less consistent in the use of intratracheal surfactant, even in extremely premature infants. A lesson from the past was the discovery that hypocarbia is associated with development of Periventricular Leukomalacia (PVL), associated with use of high frequency ventilation inducing hypocarbia and decreased cerebral blood flow [50-53]. Trials are underway using "permissive hypercarbia", with $\mathrm{CO}_{2}$ levels as high as $60-80 \mathrm{mmHg}$, to reduce the incidence of chronic lung disease [54]. However, hypercarbia increases cerebral blood flow and causes a loss of protective cerebral blood flow 
autoregulation; the cerebral blood flow becomes pressure passive with $\mathrm{pCO}_{2}>45 \mathrm{mmHg}$ [55]. Loss of autoregulation allows an increase in cerebral blood flow variability that has been associated with an increase in the frequency of severe IVH [56,57]. Thus, caution is warranted in the use of extreme hypercarbia, especially during the first week of life, in the management of extremely premature infants. Long-term neurodevelopmental outcomes for infants managed with "permissive hypercapnia", and attendant changes in cerebral blood flow are uncertain [58-61]. Thome et al. noted that in the group managed with permissive hypercapnea $\left(\mathrm{pCO}_{2}\right.$ 55-65 $\left.\mathrm{mmHg}\right)$, compared with normocapneic management $(35-45 \mathrm{mmHg}$ ), there was a significant increase in developmental impairment or death at 18-22 months corrected age [60]. The study was terminated early due to an increase in severe IVH or death in the hypercapnea group. Hagen et al. noted an increase in the rate of severe IVH in infants with a one-minute Apgar score $<4$ that were managed with permissive hypercapnea [61]. The cardiovascular and neurodevelopmental concerns associated with increasing levels of permissive hypercapnea make it increasingly important to study longterm outcomes when strategies such as Noninvasive Positive Pressure Ventilation (NIPPV) are used to avoid endotracheal intubation.

\section{Inhaled Nitric Oxide and Sildenafil}

An alternative strategy to prevent BPD is to use inhaled Nitric Oxide (iNO), a potent pulmonary vasodilator to reduce oxidant damage and improve ventilation-perfusion matching in premature infants with RDS. Several large studies have examined use of iNO for the prevention of BPD in premature infants with promising results [62-65]. Meta-analysis of the major iNO randomized control trials show a slight decrease in the combined outcome of death or BPD in the iNO groups, but the data are insufficient for recommendation of iNO for treatment of RDS in premature infants at this time $[66,67]$. Another cautionary note is that $\mathrm{iNO}$ is a potent pulmonary vasodilator that may be given to a group at high risk for PDA. However, there was no significant increase in PDA in infants receiving iNO 5 ppm [63]. In another study of patients with BPD and pulmonary hypertension, there was near normalization of pulmonary artery pressure and pulmonary vascular resistance with either $100 \%$ oxygen or iNO [48]. Pulmonary vasoconstriction may be the predominant mechanism of pulmonary hypertension in this select group of patients with BPD, rather than a developmental change in lung architecture. Thus, the pulmonary hypertension of BPD may be treatable. While iNO therapy remains expensive (reimbursement is not yet approved by most insurers), it may become an essential future therapy.

Patients with BPD have lungs with large alveoli and reduced septation and vascularity, sometimes in association with pulmonary hypertension. The mechanism may be oxidant stress, lung inflammation, or respiratory tract infection. Park et al. [68] proposed a molecular mechanism by which sildenafil decreases the oxidant stress leading to chronic lung disease in a rat model of bronchopulmonary dysplasia. Sildenafil blocks phosphodiesterase Type 5, increasing the intracellular messenger of endothelial nitric oxide and reducing pulmonary vascular resistance. Sildenafil-treated rats had improved pulmonary vascularization. Furthermore, the oxygen sensor hypoxia-inducible factor 1/2 alpha (HIF) and the angiogenic factor Vascular Endothelial Growth Factor (VEGF) were highly expressed in the lungs of sildenafiltreated rats. HIF and its downstream genes, including the VEGF, were induced by sildenafil at both the protein and the mRNA levels. Park suggests that HIF may be used to treat patients with bronchopulmonary dysplasia. VEGF is down-regulated in lungs of patients with BPD. Nitric oxide also mediates neovascularization and enforces the angiogenic effect of VEGF in lung tissue. Inhaled nitric oxide reduces the risk of bronchopulmonary dysplasia in premature infants with respiratory deficiency. Neonatologists should be monitoring future studies using iNO and/or sildenafil and their metabolites in premature infants at high risk for developing chronic lung disease.

\section{Patent Ductus Arteriosus (PDA)}

Medical and surgical management of PDA has become one of the more controversial therapies in neonatology. PDA has long been associated with increased morbidity and mortality $[67,69]$. Surgical ligation of PDA by open thoracotomy historically limited the enthusiasm for aggressive management of PDA. In 1976, medical closure of PDA with the cyclo-oxygenase inhibitor, indomethacin was reported [70,71]. Confirmation of the safety and efficacy of cyclooxygenase inhibitors opened an era of aggressive management of PDAs [72-74]. Neonatologists and pediatric cardiologists treated PDAs with indomethacin and/or surgery, to decrease the risk of chronic lung disease, pulmonary hemorrhage, and severe intraventricular hemorrhage [75]. Nonetheless, studies found that indomethacin caused transient decreases in renal function and urine output, decreases in cerebral and intestinal blood flow, and increased frequency of necrotizing enterocolitis [76]. Futhermore, PDA closure was occasionally induced in patients with previously undiagnosed ductaldependent congenital heart disease. Also, indomethacin, when given in the presence of concomitant steroid therapy, increased the incidence of intestinal perforation [13-16]. Ibuprofen was introduced as a drug that would close PDA without the undesirable vascular effects of indomethacin on renal and intestinal blood flow [77]. However, when ibuprofen was used prophylactically for PDA, there were rare instances of acute onset pulmonary hypertension in extremely premature infants, requiring treatment with iNO [78-80]. Further, ibuprofen did not decrease the frequency of NEC. The initial enthusiasm for ibuprofen waned, and intravenous ibuprofen is currently unavailable in the US.

The Trial of Indomethacin Prophylaxis in Preterms (TIPP) represents the most comprehensive clinical investigation of the effects of indomethacin and PDA on later development of the major morbidities of prematurity. The TIPP trial [81-83] showed that prophylactic indomethacin produced a significant reduction in PDA and severe intraventricular hemorrhage, but no benefit in longterm neurological outcome or the incidence of chronic lung disease. The original data analysis showed no reduction in the frequency of pulmonary hemorrhage in patients receiving indomethacin, in spite of a marked reduction in PDAs. Since a previous study had shown an association between PDA and pulmonary hemorrhage [84], the lack of this finding in the TIPP analysis may have been due to grouping of all bloody tracheal aspirates into the category of pulmonary hemorrhage. Refining the analysis to serious pulmonary hemorrhages, a post-hoc analysis of the TIPP data showed that serious pulmonary hemorrhage was less frequent in infants receiving indomethacin prophylaxis and that $80 \%$ of this difference was potentially accounted for the reduction in PDA [85]. Nonetheless, there was no significant difference in chronic lung disease or death between patients receiving indomethacin prophylaxis or placebo. Thus, while there is an association between PDA, pulmonary hemorrhage, and chronic lung disease [83-86], PDA has not been shown to cause pulmonary hemorrhage and may be a consequence of severe RDS and/or the treatment we provide.

The Caffeine for Apnea of Prematurity (CAP) trial showed that early administration of caffeine in premature infants resulted in earlier extubation from mechanical ventilation and fewer patients with PDA [87]. Since caffeine does not have a direct effect on constriction of the PDA, the effect of caffeine on PDA closure is probably due to 
the salutary effect of caffeine on lung function [88]. Similarly, a more rapidly-acting surfactant that allows earlier extubation was associated with fewer patients treated for PDA [89]. Over the past 5 years, a more conservative approach to PDA treatment has shown surprisingly little impact on long-term outcome, with some editorials suggesting that we may no longer need to treat most PDA's $[90,91]$. While there are still PDAs that require intervention, many neonatologists are now approaching PDAs more conservatively, at least in the infants $>27$ weeks, waiting for clinical signs of decompensation before initiating treatment.

\section{Postnatal Steroids}

Human fetuses and newborns do not produce cortisol de novo before 23 weeks gestation [92]. In utero, they are able to utilize maternal precursors to synthesize cortisol, but after delivery and separation from the placenta, low cortisol levels are seen and have been associated with increased mortality in premature infants [93]. Adrenal insufficiency in preterm infants is associated with an amplified inflammatory response and increased frequency of BPD [94]. Attempts to avoid this adrenal insufficiency by early neonatal treatment with physiologic doses of hydrocortisone were associated with an increased frequency of spontaneous intestinal perforation, especially when combined with concomitant indomethacin treatment [16]. Complications arising from the use of postnatal glucocorticoids in premature infants for prevention of BPD and to facilitate extubation were recently reviewed [95]. Some of the complications of systemic steroid use may be due to the response of regional vascular beds to the vasoconstriction induced by vasoactive hormones $[96,97]$. While the cause of the intestinal perforation was not established $[14,98,99]$, the combination of steroids and indomethacin is known to increase smooth muscle vasoconstriction [96] and may contribute to late-onset transient hypertension seen in many infants with chronic lung disease. An additional effect of high dose dexamethasone treatment is the development of left ventricular hypertrophy $[100,101]$. The authors describe a transient increase in left ventricular thickness associated with decreased end-diastolic dimension that equates to no change in left ventricular mass. Thus, there appears to be a decreased diastolic filling, perhaps a decrease in diastolic compliance, associated with use of dexamethasone. Alternatively, there is an intravascular volume depletion associated with maximal treatment of chronic lung disease. It is reassuring that there is not a massive increase in the left ventricular mass associated with steroid treatment of BPD.

\section{Concluding Comments}

As with all complex biological systems, the premature neonate with RDS manifests a complex interaction with cardiovascular physiology. Understanding of the effect of standard therapies for the treatment of RDS is incomplete, particularly in regard to the effect of these therapies on developing regional vascular beds and the heart. Therapies that were considered standard of care 10 years ago are now contraindicated. While clinical care of premature neonates has advanced dramatically over the past two decades, there are still many questions that remain unanswered. A change in one aspect of therapy may render other aspects of therapy unnecessary or harmful in the new milieu. The purpose of this article is to increase the awareness of potential cardiovascular complications and affects that may be seen in the NICU and beyond into adulthood. Current and future therapies may induce remodeling of a vascular bed or the myocardium leading to consequences for patients as they mature. As a new mechanistic physiology supplants the old cardio-respiratory physiology used by the clinician, use of anticipatory therapies such as iNO and sildenafil and/or their derivatives may change the scope of practice.
Our current capacity to assess regional vascular beds in tiny premature neonates is crude and limited to Doppler and Near Infrared Spectroscopy. Newer technologies, such as changes in vascular impedance and assessment of lung volumes in non-invasively ventilated infants, may provide new insight into regional vascular responses to RDS and the efficacy of non-invasive ventilatory support. Application of new technology to address some of the mechanisms of the changes observed may lead to a new generation of improved therapies. We look forward to utilizing these advances.

\section{References}

1. Avery ME, Mead J (1959) Surface properties in relation to atelectasis and hyaline membrane disease. AMA J Dis Child 97: 517-523.

2. Fujiwara T, Maeta $\mathrm{H}$, Chida S, Morita T, Watabe $\mathrm{Y}$, et al. (1980) Artificial surfactant therapy in hyaline-membrane disease. Lancet 1: 55-59.

3. Avery CM (1998) A controlled trial of antepartum glucocorticoid treatment for prevention of the respiratory distress syndrome in premature infants, by G. C. Liggins, MB, PhD, FRCOG, and R. N. Howie, MB, MRACP, Pediatrics, 1972;50:515-525. Pediatrics 102: 250-251.

4. Crowley P (1999) Cochrane Library Issue 3, Oxford: Update Software 1999 Prophylactic corticosteroids for preterm delivery. In: Cochrane Collaboration.

5. Peltoniemi OM, Kari MA, Hallman M (2011) Repeated antenatal corticosteroid treatment: a systematic review and meta-analysis. Acta Obstet Gynecol Scand 90: 719-727

6. Roberts D, Dalziel S (2006) Antenatal corticosteroids for accelerating fetal lung maturation for women at risk of preterm birth. Cochrane Database Syst Rev. 19: CD004454

7. Kari MA, Hallman M, Eronen M, Teramo K, Virtanen M, et al. (1994) Prenatal dexamethasone treatment in conjunction with rescue therapy of human surfactant: a randomized placebo-controlled multicenter study. Pediatrics 93 : 730-736.

8. Ikegami M, Jobe AH, Newnham J, Polk DH, Willet KE, et al. (1997) Repetitive prenatal glucocorticoids improve lung function and decrease growth in preterm lambs. Am J Respir Crit Care Med 156: 178-184.

9. Antonow-Schlorke I, Muller T, Brodhun M, Wicher C, Schubert $\mathrm{H}$, et al (2007) Betamethasone-related acute alterations of microtubule-associated proteins in the fetal sheep brain are reversible and independent of age during the last onethird of gestation. Am J Obstet Gynecol 196:553.e1-6

10. McNamara MF, Bottoms SF (1998) The incidence of respiratory distress syndrome does not increase when preterm delivery occurs greater than 7 days after steroid administration. Aust N Z J Obstet Gynaecol 38: 8-10.

11. French NP, Hagan R, Evans SF, Godfrey M, Newnham JP (1999) Repeated antenatal corticosteroids: size at birth and subsequent development. Am J Obstet Gynecol 180: 114-121.

12. Fujii AM, Brown E, Mirochnick M, O'Brien S, Kaufman G (2002) Neonatal necrotizing enterocolitis with intestinal perforation in extremely premature infants receiving early indomethacin treatment for patent ductus arteriosus. J Perinatol 22: 535-540.

13. Attridge JT, Clark R, Walker MW, Gordon PV (2006) New insights into spontaneous intestinal perforation using a national data set: (1) SIP is associated with early indomethacin exposure. J Perinatol 26: 93-99.

14. Ahmad I, Davis KF, Emil S, Uy C, Sills J (2008) Risk factors for spontaneous intestinal perforation in extremely low birth weight infants. The Open Pediatric Medicine Journal 2: 11-15.

15. Gordon PV (2009) Understanding intestinal vulnerability to perforation in the extremely low birth weight infant. Pediatr Res 65: 138-144.

16. Watterberg KL, Gerdes JS, Cole CH, Aucott SW, Thilo EH, et al. (2004) Prophylaxis of early adrenal insufficiency to prevent bronchopulmonary dysplasia: a multicenter trial. Pediatrics 114: 1649-1657.

17. Kaiser JR, Gauss CH, Williams DK (2004) Surfactant administration acutely affects cerebral and systemic hemodynamics and gas exchange in very-lowbirth-weight infants. J Pediatr 144: 809-814.

18. Fujii AM, Bailey J, Doros G, Sampat K, Sikes NC, et al. (2009) Cerebra Blood Flow Responses to Beractant and Poractant Administration. Journal of Neonatal-Perinatal Medicine 2: 27-34. 
Citation: Fujii AM (2013) Cardiovascular Effects of the Treatment of Respiratory Distress Syndrome and Associated Morbidities of Prematurity. J Pulmon Resp Med S13: 005. doi:10.4172/2161-105X.S13-005

19. O'Toole SJ, Karamanoukian HL, Morin FC, Holm BA, Egan EA, et al. (1996) Surfactant decreases pulmonary vascular resistance and increases pulmonary blood flow in the fetal lamb model of congenital diaphragmatic hernia. J Pediatr Surg 31: 507-511.

20. Alexander J, Milner AD (1995) Lung volume and pulmonary blood flow measurements following exogenous surfactant. Eur J Pediatr 154: 392-397.

21. Kribs A, Pillekamp F, Hünseler C, Vierzig A, Roth B (2007) Early administration of surfactant in spontaneous breathing with nCPAP: feasibility and outcome in extremely premature infants (postmenstrual age $</=27$ weeks).Paediatr Anaesth 17:364-369.

22. Kribs A, Härtel C, Kattner E, Vochem M, Küster H, et al. (2010) Surfactant without intubation in preterm infants with respiratory distress: first multi-center data. Klin Padiatr 222: 13-17.

23. Dargaville PA, Aiyappan A, Cornelius A, Williams C, De Paoli AG (2011) Preliminary evaluation of a new technique of minimally invasive surfactant therapy. Arch Dis Child Fetal Neonatal Ed 96: F243-248.

24. Dargaville PA, Aiyappan A, De Paoli AG, Kuschel CA, Kamlin CO, et al. (2011) Minimally-invasive surfactant therapy in preterm infants on continuous positive airway pressure. Arch Dis Child Fetal Neonatal Ed 96: F243-F248.

25. Göpel W, Kribs A, Ziegler A, Laux R, Hoehn T, et al. (2011) Avoidance of mechanical ventilation by surfactant treatment of spontaneously breathing preterm infants (AMV): an open-label, randomised, controlled trial. Lancet 378 : 1627-1634.

26. Kanmaz HG, Erdeve O, Canpolat FE, Mutlu B, Dilmen U (2013) Surfactant administration via thin catheter during spontaneous breathing: randomized controlled trial. Pediatrics 131: e502-509.

27. Finer NN, Merritt TA, Bernstein G, Job L, Mazela J, et al. (2010) An open label, pilot study of Aerosurf $\circledast$ combined with nCPAP to prevent RDS in preterm neonates. J Aerosol Med Pulm Drug Deliv 23: 303-309.

28. Bancalari E, del Moral T (2001) Bronchopulmonary dysplasia and surfactant. Biol Neonate 80 Suppl 1: 7-13.

29. Manktelow BN, Draper ES, Annamalai S, Field D (2001) Factors affecting the incidence of chronic lung disease of prematurity in 1987, 1992, and 1997. Arch Dis Child Fetal Neonatal Ed 85: F33-35.

30. Avery ME, Tooley WH, Keller JB, Hurd SS, Bryan MH, et al. (1987) Is chronic lung disease in low birth weight infants preventable? A survey of eight centers. Pediatrics 79: 26-30.

31. Horbar JD, McAuliffe TL, Adler SM, Albersheim S, Cassady G, et al. (1988) Variability in 28-day outcomes for very low birth weight infants: an analysis of 11 neonatal intensive care units. Pediatrics 82: 554-559.

32. Van Marter LJ, Allred EN, Pagano M, Sanocka U, Parad R, et al. (2000) Do clinical markers of barotrauma and oxygen toxicity explain interhospital variation in rates of chronic lung disease? The Neonatology Committee for the Developmental Network. Pediatrics 105: 1194-201.

33. Verder H, Robertson B, Greisen G, Ebbesen F, Albertsen P, et al. (1994) Surfactant therapy and nasal continuous positive airway pressure for newborns with respiratory distress syndrome. Danish-Swedish Multicenter Study Group. N Engl J Med 331: 1051-1055.

34. Verder H, Albertsen P, Ebbesen F, Greisen G, Robertson B, et al. (1999) Nasa continuous positive airway pressure and early surfactant therapy for respiratory distress syndrome in newborns of less than 30 weeks' gestation. Pediatrics 103: E24.

35. Bhandari V, Gavino RG, Nedrelow JH, Pallela P, Salvador A, et al. (2007) A randomized controlled trial of synchronized nasal intermittent positive pressure ventilation in RDS. J Perinatol 27: 697-703.

36. Morley CJ, Davis PG, Doyle LW, Brion LP, Hascoet JM, et al. (2008) Nasal CPAP or intubation at birth for very preterm infants. N Engl J Med 358: 700-708.

37. SUPPORT Study Group of the Eunice Kennedy Shriver NICHD Neonatal Research Network, Finer NN, Carlo WA, Walsh MC, Rich W, et al. (2010) Early CPAP versus surfactant in extremely preterm infants. N Engl J Med 362: 1970 1979.

38. Sandri F, Plavka R, Ancora G, Simeoni U, Stranak Z, et al. (2010) Prophylactic or early selective surfactant combined with nCPAP in very preterm infants. Pediatrics 125: e1402-1409.

39. Dreyfuss D, Saumon G (1998) Ventilator-induced lung injury: lessons from experimental studies. Am J Respir Crit Care Med 157: 294-323.
40. Greenough A Milner AD, Dimitriou G (2001) Synchronize mechanica ventilation for respiratory support in newborn infants. Cochrane Database Syst Rev. 2001: CD 000456

41. Zaher TE, Miller EJ, Morrow DM, Javdan M, Mantell LL (2007) Hyperoxiainduced signal transduction pathways in pulmonary epithelial cells. Free Radic Biol Med 42: 897-908.

42. Li LF, Liao SK, Ko YS, Lee CH, Quinn DA (2007) Hyperoxia increases ventilatorinduced lung injury via mitogen-activated protein kinases: a prospective, controlled animal experiment. Crit Care 11: R25.

43. Kotecha S (1996) Cytokines in chronic lung disease of prematurity. Eur Pediatr 155 Suppl 2: S14-17.

44. Speer CP (2001) New insights into the pathogenesis of pulmonary inflammation in preterm infants. Biol Neonate 79: 205-209.

45. Abman SH (2001) Bronchopulmonary dysplasia: "a vascular hypothesis". Am J Respir Crit Care Med 164: 1755-1756.

46. Bhatt AJ, Pryhuber GS, Huyck H, Watkins RH, Metlay LA, et al. (2001) Disrupted pulmonary vasculature and decreased vascular endothelial growth factor. Flt1 , and TIE-2 in human infants dying with bronchopulmonary dysplasia. Am J Respir Crit Care Med 164: 1971-1980.

47. Lassus P, Turanlahti M, Heikkilä P, Andersson LC, Nupponen I, et al. (2001) Pulmonary vascular endothelial growth factor and Flt-1 in fetuses, in acute and chronic lung disease, and in persistent pulmonary hypertension of the newborn. Am J Respir Crit Care Med 164: 1981-1987.

48. Mourani PM, Ivy DD, Gao D, Abman SH (2004) Pulmonary vascular effects of inhaled nitric oxide and oxygen tension in bronchopulmonary dysplasia. Am J Respir Crit Care Med 170: 1006-1013.

49. Northway WH Jr, Rosan RC, Porter DY (1967) Pulmonary disease following respirator therapy of hyaline-membrane disease. Bronchopulmonary dysplasia. N Engl J Med 276: 357-368.

50. Wiswell TE, Graziani LJ, Kornhauser MS, Stanley C, Merton DA, et al. (1996) Effects of hypocarbia on the development of cystic periventricular leukomalacia in premature infants treated with high-frequency jet ventilation. Pediatrics 98 918-924.

51. Okumura A, Hayakawa F, Kato T, Itomi K, Maruyama K, et al. (2001) Hypocarbia in preterm infants with periventricular leukomalacia: the relation between hypocarbia and mechanical ventilation. Pediatrics 107: 469-475.

52. Shankaran S, Langer JC, Kazzi SN, Laptook AR, Walsh M (2006) Cumulative index of exposure to hypocarbia and hyperoxia as risk factors for periventricular leukomalacia in low birth weight infants. Pediatrics 118: 1654-1659.

53. Resch B, Neubauer K, Hofer N, Resch E, Maurer U, et al. (2012) Episodes of hypocarbia and early-onset sepsis are risk factors for cystic periventricular leukomalacia in the preterm infant. Early Hum Dev 88: 27-31.

54. Thome UH, Ambalavanan N (2009) Permissive hypercapnia to decrease lung injury in ventilated preterm neonates. Semin Fetal Neonatal Med 14: 21-27.

55. Kaiser JR, Gauss CH, Williams DK (2005) The effects of hypercapnia on cerebral autoregulation in ventilated very low birth weight infants. Pediatr Res 58: 931-935.

56. Tsuji M, Saul JP, du Plessis A, Eichenwald E, Sobh J, et al. (2000) Cerebral intravascular oxygenation correlates with mean arterial pressure in critically ill premature infants. Pediatrics 106: 625-632.

57. Soul JS, Hammer PE, Tsuji M, Saul JP, Bassan H, et al. (2007) Fluctuating pressure-passivity is common in the cerebral circulation of sick premature infants. Pediatr Res 61: 467-473.

58. Mariani G, Cifuentes J, Carlo WA (1999) Randomized trial of permissive hypercapnia in preterm infants. Pediatrics 104: 1082-1088.

59. Carlo WA, Stark AR, Wright LL, Tyson JE, Papile LA, et al. (2002) Minima ventilation to prevent bronchopulmonary dysplasia in extremely-low-birthweight infants. J Pediatr 141: 370-374.

60. Thome UH, Carroll W, Wu TJ, Johnson RB, Roane C, et al. (2006) Outcome of extremely preterm infants randomized at birth to different $\mathrm{PaCO} 2$ targets during the first seven days of life. Biol Neonate 90: 218-225.

61. Hagen EW, Sadek-Badawi M, Carlton DP, Palta M (2008) Permissive hypercapnia and risk for brain injury and developmental impairment. Pediatrics 122: e583-589. 
Citation: Fujii AM (2013) Cardiovascular Effects of the Treatment of Respiratory Distress Syndrome and Associated Morbidities of Prematurity. J Pulmon Resp Med S13: 005. doi:10.4172/2161-105X.S13-005

Page 6 of 6

62. Ballard RA, Truog WE, Cnaan A, Martin RJ, Ballard PL, et al. (2006) Inhaled nitric oxide in preterm infants undergoing mechanical ventilation. $\mathrm{N}$ Engl $\mathrm{J}$ Med 355: 343-353.

63. Kinsella JP, Cutter GR, Walsh WF, Gerstmann DR, Bose CL, et al. (2006) Early inhaled nitric oxide therapy in premature newborns with respiratory failure. $\mathrm{N}$ Engl J Med 355: 354-364.

64. Schreiber MD, Gin-Mestan K, Marks JD, Huo D, Lee G, et al. (2003) Inhaled nitric oxide in premature infants with the respiratory distress syndrome. $\mathrm{N} \mathrm{Eng}$ J Med 349: 2099-2107.

65. Van Meurs KP, Wright LL, Ehrenkranz RA, Lemons JA, Ball MB, et al. (2005) Inhaled nitric oxide for premature infants with severe respiratory failure. $\mathrm{N}$ Engl J Med 353: 13-22.

66. Allen MC, Donohue P, Gilmore M, Cristofalo E, Wilson RF, et al. (2010) Inhaled Nitric Oxide in preterm infants. Evidence Report/Technology Assessment No 195 (Prepared by Johns Hopkins University Evidence-based Practice Cente under Contract No 290-2007-10061-1). AHRQ Publication No 11-E001. Rockville, MD: Agency for Healthcare Research and Quality.

67. Abbott ME (1936) Atlas of congenital heart disease. New York, American Heart Association

68. Park HS, Park JW, Kim HJ, Choi CW, Lee HJ, et al. (2013) Sildenafil alleviates bronchopulmonary dysplasia in neonatal rats by activating the hypoxiainducible factor signaling pathway. Am J Respir Cell Mol Biol 48: 105-113.

69. Gross RE, Hubbard JP (1939) Surgical ligation of a patent ductus arteriosus, report of the first successful case. JAMA 112: 729-31.

70. Friedman WF, Hirschklau MJ, Printz MP, Pitlick PT, Kirkpatrick SE (1976) Pharmacologic closure of patent ductus arteriosus in the premature infant. $\mathrm{N}$ Engl J Med 295: 526-529.

71. Heymann MA, Rudolph AM, Silverman NH (1976) Closure of the ductus arteriosus in premature infants by inhibition of prostaglandin synthesis. $\mathrm{N}$ Eng J Med 295: 530-533.

72. Gersony WM, Peckham GJ, Ellison RC, Miettinen OS, Nadas AS (1983) Effects of indomethacin in premature infants with patent ductus arteriosus: results of a national collaborative study. J Pediatr 102: 895-906.

73. Ellison RC, Peckham GJ, Lang P, Talner NS, Lerer TJ, et al. (1983) Evaluation of the preterm infant for patent ductus arteriosus. Pediatrics $71: 364-372$.

74. Van Overmeire B, Van de Broek H, Van Laer P, Weyler J, Vanhaesebrouck $P$ (2001) Early versus late indomethacin treatment for patent ductus arteriosus in premature infants with respiratory distress syndrome. J Pediatr 138: 205-211.

75. Ment LR, Oh W, Ehrenkranz RA, Philip AG, Vohr B, et al. (1994) Low-dose indomethacin and prevention of intraventricular hemorrhage: a multicenter randomized trial. Pediatrics 93: 543-550.

76. Grosfeld JL, Chaet M, Molinari F, Engle W, Engum SA, et al. (1996) Increased risk of necrotizing enterocolitis in premature infants with patent ductus arteriosus treated with indomethacin. Ann Surg 224: 350-355.

77. Aranda JV, Clyman R, Cox B, Van Overmeire B, Wzniak P, et al. (2009) A randomized, double-blind, placebo-controlled trial on intravenous ibuprofen L-Lysine for the early closure of non-symptomatic patent ductus arteriosus within 72 hours of birth in extremely low birthweight infants. Amer J Perinato 26:235-245.

78. Gournay V, Savagner C, Thiriez G, Kuster A, Rozé JC (2002) Pulmonary hypertension after ibuprofen prophylaxis in very preterm infants. Lancet 359 1486-1488.

79. Bellini C, Campone F, Serra G (2006) Pulmonary hypertension following L-lysine ibuprofen therapy in a preterm infant with patent ductus arteriosus. CMAJ 174: 1843-1844

80. Amendolia B, Lynn M, Bhat V, Ritz SB, Aghai ZH (2012) Severe pulmonary hypertension with therapeutic L-lysine ibuprofen in 2 preterm neonates. Pediatrics 129: e1360-1363.

81. Schmidt B, Davis P, Moddemann D, Ohlsson A, Roberts RS, et al. (2001) Long term effects of indomethacin prophylaxis in extremely-low-birth-weight infants. N Engl J Med 344: 1966-1972.

82. Schmidt B, Roberts RS, Fanaroff A, Davis P, Kirpalani HM, et al. (2006) Indomethacin prophylaxis, patent ductus arteriosus, and the risk of bronchopulmonary dysplasia: further analyses from the Trial of Indomethacin Prophylaxis in Preterms (TIPP). J Pediatr 148: 730-734.
83. Kabra NS, Schmidt B, Roberts RS, Doyle LW, Papile L, et al. (2007) Neurosensory impairment after surgical closure of patent ductus arteriosus in extremely low birth weight infants: results from the Trial of Indomethacin Prophylaxis in Preterms. J Pediatr 150: 229-234, 234.

84. Kluckow M, Evans N (2000) Ductal shunting, high pulmonary blood flow, and pulmonary hemorrhage. J Pediatr 137: 68-72.

85. Alfaleh K, Smyth JA, Roberts RS, Solimano A, Asztalos EV, et al. (2008) Prevention and 18-Month Outcomes of Serious Pulmonary Hemorrhage in Extremely Low Birth Weight Infants: Results From the Trial of Indomethacin Prophylaxis in Preterms. Pediatrics 121; e233-e238

86. Clyman RI, Saha S, Jobe A, Oh W (2007) Indomethacin prophylaxis for preterm infants: the impact of 2 multicentered randomized controlled trials on clinical practice. J Pediatr 150: 46-50.

87. Schmidt B, Roberts RS, Davis P, Doyle LW, Barrington KJ, et al. (2006) Caffeine therapy for apnea of prematurity. N Engl J Med 354: 2112-2121.

88. Clyman RI, Roman C (2007) The effects of caffeine on the preterm sheep ductus arteriosus. Pediatr Res 62: 167-169.

89. Fujii A, Allen R, Doros G, O'Brien S (2010) Patent ductus arteriosus hemodynamics in very premature infants treated with poractant alfa or beractant for respiratory distress syndrome. J Perinatol, 2010; 30: 671-676.

90. Benitz WE (2012) Patent ductus arteriosus: to treat or not to treat? Arch Dis Child Fetal Neonatal Ed 97: F80-82.

91. Adrouche-Amrani L, Green RS, Gluck KM, Lin J (2012) Failure of a repeat course of cyclooxygenase inhibitor to close a PDA is a risk factor for developing chronic lung disease in ELBW infants. BMC Pediatr 12: 10

92. Mesiano S, Jaffe RB (1997) Developmental and functional biology of the primate fetal adrenal cortex. Endocr Rev 18: 378-403.

93. Scott SM, Cimino DF (2004) Evidence for developmental hypopituitarism in ill preterm infants. J Perinatol 24: 429-434.

94. Watterberg KL, Scott SM (1995) Evidence of early adrenal insufficiency in babies who develop bronchopulmonary dysplasia. Pediatrics 95: 120-125

95. Watterberg KL; American Academy of Pediatrics Committee on Fetus and Newborn. (2010) Policy statement--postnatal corticosteroids to prevent or treat bronchopulmonary dysplasia. Pediatrics 126: 800-808

96. Ullian ME (1999) The role of corticosteriods in the regulation of vascular tone Cardiovasc Res 41: 55-64.

97. Roghair RD, Segar JL, Sharma RV, Zimmerman MC, Jagadeesha DK, et al. (2005) Newborn lamb coronary artery reactivity is programmed by early gestation dexamethasone before the onset of systemic hypertension. Am J Physiol Regul Integr Comp Physiol 289: R1169-1176.

98. Gordon PV, Herman AC, Marcinkiewicz M, Gaston BM, Laubach VE, et al. (2007) A neonatal mouse model of intestinal perforation: investigating the harmful synergism between glucocorticoids and indomethacin. J Pediatr Gastroenterol Nutr 45: 509-519.

99. Roghair RD, Volk KA, Lamb FS, Segar JL (2012) Impact of materna dexamethasone on coronary PGE(2) production and prostaglandin-dependent coronary reactivity. Am J Physiol Regul Integr Comp Physiol 303: R513-519.

100. Werner JC, Sicard RE, Hansen TW, Solomon E, Cowett RM, et al. (1992) Hypertrophic cardiomyopathy associated with dexamethasone therapy for bronchopulmonary dysplasia. J Pediatr 120: 286-291.

101. Bensky AS, Kothadia JM, Covitz W (1996) Cardiac effects of dexamethasone in very low birth weight infants. Pediatrics 97: 818-821.

This article was originally published in a special issue, Controversies in the Management of Respiratory Distress Syndrome in Premature Neonates handled by Editor(s). Dr. Alan Fujii, Boston University, USA 